\title{
Differential effects of ovarian local anaesthesia during pro-oestrus on ovulation by the right or left ovary in normal and hemi-ovariectomized adult rats
}

\author{
R. Domínguez, M. E. Cruz and C. Morán \\ Research Unit in Biology of Reproduction, Facultad de Estudios Superiores Zaragoza, Universidad Nacional \\ Autónoma de México, AP 9-020, CP 15000, México DF, México
}

\begin{abstract}
The effects on spontaneous ovulation in normal and hemi-ovariectomized cyclic rats of an injection of saline or a local anaesthetic (2-diethylamine-2', $6^{\prime}$-acetoxilidide hydrochloride with adrenaline, Xylocaine; administered at 13:00 h) into the bursa ovarica, were studied to investigate the participation of ovarian innervation in the regulation of the response of ovarian follicles to endogenous gonadotrophins on the day of pro-oestrus. The injection of saline or Xylocaine into both ovaries did not affect ovulation by the right ovary. Bilateral injection of Xylocaine did not affect ovulation by the left ovary. However, when saline was injected into the right ovary and Xylocaine into the left ovary, the number of ova shed by the left ovary decreased significantly $(0.9 \pm 0.7$ versus $4.4 \pm 0.2, P<0.01$; Mann-Whitney $U$ test). In hemi-ovariectomized animals, when the right ovary was anaesthetized, ovulation was similar to that in saline-treated animals, and when the right ovary was anaesthetized, ovulation was blocked (one of six animals ovulated). The injection of hCG at 14:00 h to hemi-ovariectomized rats did not restore ovulation, whereas all the rats ovulated when anaesthesia occurred at 18:00 $\mathrm{h}$. The present results suggest that on the afternoon of the day of pro-oestrus, before the LH peak, a neural signal modulates the response of the left ovary to gonadotrophins.
\end{abstract}

\section{Introduction}

There is evidence that ovarian innervation plays an important role in the regulation of ovarian functions (Burden, 1985; Ojeda and Aguado, 1985). However, the participation of ovarian innervation in the regulation of ovulation is controversial. For example, ovarian autografts in spayed animals ovulate normally (Domínguez and Riboni, 1971) and ovulation can be induced in vitro using perfusion systems (Higuchi and Spey, 1989; Janson et al., 1988). Similarly, the bilateral section of the superior ovarian nerve performed on different days of the oestrous cycle (Chávez et al., 1991) or the freezing of both nerves (Wylie et al., 1985) do not alter ovulation. In addition, denervation of the ovary did not influence ovulation, pregnancy or corpora lutea in rabbits (Weiner et al., $1975 a, b, c)$. On the basis of these and other observations, Espey and Lipner (1994) concluded that "... although one cannot completely rule out the possibility that adrenergic agents might have some modest influence on ovulation, it is, nevertheless, quite apparent that nervous activity is not an essential component of the ovulatory mechanism".

There is evidence suggesting that ovarian innervation plays a definitive role in the regulation of the ovulatory process. Ovarian autograft in hemispayed rats did not present signs of ovulation or follicular growth (Domínguez and Riboni, 1971).

Revised manuscript received 2 October 1997
Sequential administration of FSH and hCG induced follicular growth but not ovulation. However, when the same treatment was performed on peripheral sympathetic-denervated animals that had been administered guanethidine, signs of ovulation were present in the graft (Ayala and Domínguez, 1988). The unilateral and bilateral section of the vagus nerve affects spontaneous and gonadotrophin-induced ovulation (Cruz et al., 1986; Chávez et al., 1987a, b). The unilateral section of the superior ovarian nerve affects ovulation by the denervated ovary, while the intact ovary presents a compensatory ovulation (Chávez et al., 1991; Morales et al., 1993) and the denervated ovary does not increase the number of ova shed after the injection of hCG and pregnant mares' serum gonadotrophin, or the sequential administration of both hormones (Morales and Chávez, 1994). Local anaesthesia or the lesion of the cervico-vaginal plexus also affects ovulation (Domínguez, 1990).

The participation of the neural signals in the regulation of ovulation can be explained as modulatory effects that use neurotransmitters (catecholamines, neuropeptides, acetylcholine) released at appropriate times to influence the response of the follicle to gonadotrophins.

Although it is thought, in general, that paired organs are physiologically and pathologically very similar, there is evidence that endocrine paired organs are not identical in their function and control. For example, in genetically female intersex pigs with ovotestes, the higher degree of masculinization 
occurs on the right gonad (Hunter et al, 1985). In women, ovulation occurs in the right ovary twice as often as in the left one (Potashnik et al., 1987). A similar difference has been described in monkeys by Morse and Van Wagenen (1936). According to Bernstein (1993) " ... endocrine asymmetry is a subset of a broader phenomenon which may be called topoendocrinology (topological endocrinology). Topoendocrinology analyses 'spatial' (topographical) peculiarities of the functioning of the endocrine system.",

There is evidence that the neuroendocrine mechanisms regulating ovulation in hemi-ovariectomized animals are different from those occurring in normal animals, and that the mechanisms participating are different for the right and left ovary and depend on the ovarian innervation (Chávez ef al., 1987c; Domínguez et al., 1989). For example, the unilateral section of the left vagus nerve affected ovulation in rats with one or both ovaries in different ways (Cruz et al., 1986; Chávez et al., 1987a, b). The unilateral section of the superior ovarian nerve, which affects ovulation when the animal has both ovaries, had no effect when the animal was hemiovariectomized and the results depended on the day of the oestrous cycle when the treatment was performed (Chávez and Domínguez, 1994).

The rationale for the present study was that on the day of pro-oestrus, the effects of gonadotrophins on the ovulatory process are modulated by neural information reaching the ovary, which would be different for the right and left ovary, and also in intact and hemi-ovariectomized animals. The effects on ovulation of a local anaesthetic, 2-diethylamine-2',6'acetoxilidide hydrochloride with adrenaline, injected into the bursa ovarica at the beginning of pro-oestrus in the afternoon, were analysed to test this hypothesis.

\section{Materials and Methods}

Adult virgin female rats of the C-II-Z-V strain from the authors' stock were kept under lighting controlled conditions (lights on from 05:00 to 19:00 h) with food and tap water available ad libitum.

The oestrous cycle was monitored by daily vaginal smears, and only those rats with three consecutive 4 day cycles were used. At 13:00 h on the day of pro-oestrus, the animals were anaesthetized with ether and allotted at random to one of the following experiments, and killed $20 \mathrm{~h}$ later.

\section{Experiment 1: effects on ounlation after the unilateral injection of} $\chi_{y}$ locaine into the ovaries or unilateral injection of saline in normal rats

Rats were anaesthetized and laparotomies were performed; the right or left ovary were exposed, and saline or lidocaine (20 mg 2-dieltilamine-2',20. 6'-acetoxilidide clorhidrate $\mathrm{ml}^{-1}$ ) with $0.01 \mathrm{mg}$ adrenaline (Xylocaine) $\mathrm{ml}^{-1}$ (Astra Chemicals, Naucalpan, México) was injected into the bursa. The bursa ovarica was distended by the fluid injected. The abdominal wall and the skin were sutured. Two groups of rats were anaesthetized and laparotomies were performed, and had the right or left ovary exposed and returned to the abdominal cavity and the wound was sutured (unilateral manipulation of the ovary
Table 1. Treatments used in Experiment 2

\begin{tabular}{lcccc}
\hline & Group 1 & Group 2 & Group 3 & Group 4 \\
\hline $\begin{array}{l}\text { Right ovary } \\
\text { Left ovary }\end{array}$ & Saline & Xylocaine & Xylocaine & $\begin{array}{c}\text { Saline } \\
\text { Xaline }\end{array}$ \\
\hline
\end{tabular}

groups) for comparison. In addition, an untreated control group was killed on the morning of the day of oestrus, after three consecutive 4 day cycles.

Experiment 2: comparison of ovulation by the right and left ovary to the effects of the bilateral injection of saline or Xylocaine

A group of cyclic rats was ether anaesthetized, laparotomies were performed and animals were alloted at random to the following experimental groups (Table 1): group 1 : the left and right ovary were exposed, and with the aid of a $1 \mathrm{ml}$ syringe and a 25 needle, $0.1 \mathrm{ml}$ of saline was injected into the bursa ovarica of the right and left ovary; group 2: Xylocaine was injected into the bursa ovarica of the right and left ovary; group 3: saline was injected into the bursa of the right ovary, while Xylocaine was injected into the bursa of the left ovary; and group 4: saline was injected into the left ovary and Xylocaine into the right ovary.

The bursa ovarica was distended by the fluid injected. The abdominal wall and the skin were sutured.

For comparison, a group of rats was anaesthetized, laparotomies were performed and animals had both ovaries exposed and returned to the abdominal cavity and the wound sutured (bilateral manipulation of the ovary group).

Experiment 3: effects on ovulation after the unilateral injection of $x_{y}$ locaine into the ovaries or unilateral injection of saline to hemi-ovariectomized rats

Rats were anaesthetized and laparotomies were performed, and the right or left ovary was exposed and saline or Xylocaine was injected into the bursa. Two minutes after the injection of saline or Xylocaine, the untreated ovary was exposed and extirpated.

On the basis of the results obtained, a group of rats was injected with Xylocaine into the bursa ovarica of the left ovary and right hemi-ovariectomized 2 min later (left ovary in situ), and then injected $\mathrm{I} \mathrm{h}$ later (14:00 h of pro-oestrus) with $10 \mathrm{iu}$ hCG (Sigma Chemical Co., St Louis MO), subcutaneously. In another experiment, the treatment (Xylocaine injection into the bursa of the left ovary, and extirpation of the right one) was performed at 18:00 h on the day of pro-oestrus. Both groups of animals were autopsied on the morning of the next day.

In another experiment, the left or right ovary was injected with Xylocaine at 13:00 h, and 2 min later the 'anaesthetized' ovary was extirpated.

Animals were killed by bleeding under ether anaesthesia, on the next morning (on the expected day of oestrus). At autopsy, the oviducts were dissected and the ova were counted with the aid of a dissecting microscope. The ovaries of non-ovulating 
Table 2. Ovulation rate of and number of ova shed by (means \pm SEM) the right and left ovaries of untreated control rats and pro-oestrous rats injected with saline or Xylocaine into the right or left ovary and autopsied the next day

\begin{tabular}{lcccc}
\hline Treatment & $\begin{array}{c}\text { Ovulation rate } \\
\text { of right ovary }\end{array}$ & $\begin{array}{c}\text { Number of ova } \\
\text { shed by right ovary }\end{array}$ & $\begin{array}{c}\text { Ovulation rate } \\
\text { of left ovary }\end{array}$ & $\begin{array}{c}\text { Number of ova } \\
\text { shed by left ovary }\end{array}$ \\
\hline Control & $8 / 8$ & $5.6 \pm 0.3$ & $8 / 8$ & $5.5 \pm 0.8$ \\
Saline right ovary & $6 / 10$ & $4.4 \pm 0.8$ & $8 / 10$ & $5.5 \pm 1.5$ \\
Xylocaine right ovary & $8 / 11$ & $5.5 \pm 0.9$ & $9 / 11$ & $4.4 \pm 0.7$ \\
Saline left ovary & $4 / 4$ & $5.5 \pm 1.0$ & $3 / 4$ & $3.7 \pm 1.2$ \\
Xylocaine left ovary & $9 / 11$ & $5.7 \pm 0.8$ & $9 / 11$ & $4.1 \pm 0.9$ \\
\hline
\end{tabular}

Table 3. Ovulation rate of and the number of ova shed by (means \pm SEM) the ovulating ovary of untreated control rats and pro-oestrous rats injected with saline or Xylocaine and autopsied the next day

\begin{tabular}{lccccc}
\hline $\begin{array}{l}\text { Treatment on } \\
\text { right ovary }\end{array}$ & $\begin{array}{c}\text { Treatment on } \\
\text { left ovary }\end{array}$ & $\begin{array}{c}\text { Ovulation rate } \\
\text { of right ovary }\end{array}$ & $\begin{array}{c}\text { Number of ova shed } \\
\text { by right ovary }\end{array}$ & $\begin{array}{c}\text { Ovulation rate } \\
\text { of left ovary }\end{array}$ & $\begin{array}{c}\text { Number of ova shed } \\
\text { by left ovary }\end{array}$ \\
\hline Control & Control & $8 / 8$ & $5.6 \pm 0.3$ & $8 / 8$ & $5.5 \pm 0.8$ \\
Saline & Saline & $8 / 9$ & $4.6 \pm 0.5$ & $6 / 9$ & $5.4 \pm 0.7$ \\
Xylocaine & Xylocaine & $7 / 9$ & $4.4 \pm 0.7$ & $8 / 9$ & $4.7 \pm 1.0$ \\
Xylocaine & Saline & $4 / 6$ & $4.0 \pm 1.1$ & $6 / 6$ & $6.0 \pm 0.9$ \\
Saline & Xylocaine & $7 / 11$ & $2.9 \pm 0.4^{*}$ & $9 / 11$ & $1.5 \pm 0.3^{\dagger}$ \\
\hline
\end{tabular}

${ }^{*} P<0.01$ compared with control group; Kruskal-Wallis test followed by Mann-Whitney $U$ test.

${ }^{\dagger} P<0.01$ compared with control and Xylocaine-Xylocaine, and saline-saline treated groups; Kruskal-Wallis test followed by Mann-Whitney U test.

animals or those with a small number of ova in the bursa were fixed in Bouin's fluid, embedded in paraffin wax, serially sectioned at $10 \mu \mathrm{m}$, stained with haematoxylin-eosin, and examined under a light microscope for fresh corpora lutea as a sign of ovulation, or the presence of fresh corpora lutea with a trapped oocyte.

The animals were considered to have ovulated when ova were present in the oviduct or when fresh corpora lutea without trapped ova were present in the ovaries. The ovulation rate (number of rats ovulating: total number of rats treated) was analysed by Fisher's exact probability test. The number of ova recovered, or the number of fresh corpora lutea counted in ovaries, where values differed, were analysed using the Kruskal-Wallis test followed by the Mann-Whitney U test $(P<0.05$ was considered significant).

\section{Results}

The ovulation rate (number of ovulating rats: number of treated rats) was not modified by the unilateral or bilateral manipulation of the ovaries (12/12 versus $8 / 8$, not significant). The number of ova shed by ovulating animals decreased in bilaterally manipulated animals $(7.8 \pm 0.7$ versus $11.1 \pm 0.7$, $P<0.05$ Mann-Whitney $U$ test) and was not affected when the manipulation was performed on the right or left ovary $(9.8 \pm 0.8$ and $10.0 \pm 0.3$ versus $11.1 \pm 0.7$, respectively, not significant).

\section{Experiment 1}

The ovulation rate for the groups of unilateral treated rats was similar to that of untouched control animals (Table 2; 8/10, 9/11, 4/4 and 9/11 versus 8/8, not significant, Fisher's exact probability test). In ovulating animals, neither the ovulation rate for the right or left ovary nor the number of ova shed by ovulating animals was affected by unilateral treatment (Table 2).

\section{Experiment 2}

The ovulation rate for the groups of bilaterally treated rats was similar to that for untreated control animals (Table 3; 8/9, $8 / 9,6 / 6$, and $9 / 11$ versus $8 / 8$, not significant, Fisher's exact probability test). Ovulation by the right or left ovary (number of ovulating animals, and number of ova shed per animal) was not modified by the bilateral injection of saline or Xylocaine. The injection of $X y$ locaine into the right ovary and saline into the left ovary did not affect ovulation by the right ovary. Injection of saline into the right ovary and Xylocaine into the left ovary did not affect ovulation rate but decreased the number of ova in the right as well as in the left ovary (Table 3).

\section{Experiment 3}

In hemi-ovariectomized animals, injection of saline into the bursa ovarica of the left ovary modified neither the number of 
Table 4. Ovulation rate of and the number of ova shed (means \pm SEM) by in situ ovaries of pro-oestrous-hemiovariectomized rats injected with saline or Xylocaine into the bursa ovarica $2 \mathrm{~min}$ before hemi-ovariectomy and autopsied the next day

\begin{tabular}{|c|c|c|c|c|}
\hline In situ ovary & Treatment & $n$ & $\begin{array}{c}\text { Ovulation } \\
\text { rate }\end{array}$ & $\begin{array}{l}\text { Number of } \\
\text { ova shed }\end{array}$ \\
\hline Right & Saline & 5 & $5 / 5$ & $4.8 \pm 0.4$ \\
\hline Right & Xylocaine & 8 & $8 / 8$ & $4.4 \pm 0.6$ \\
\hline Left & Saline & 6 & $5 / 6$ & $5.5 \pm 0.9$ \\
\hline Left & Xylocaine & 6 & $1 / 6^{*}$ & I corpus luteum \\
\hline
\end{tabular}

${ }^{*} P<0.05$ in comparison with saline-treated groups; Fisher's exact probability test.

ovulating animals nor the number of ova recovered. Anaesthesia of the left ovary by Xylocaine injection resulted in the diminution of ovulation in almost all animals treated. One fresh corpus luteum was observed in the ovary of one animal and, in another three ovaries, one, one and two corpora lutea with trapped ova were observed. Taken together, the number of fresh corpora lutea and the number of luteinized follicles with trapped ova in those animals with Xylocaine injected into the left ovary and right hemi-ovariectomized were significantly lower than in those animals injected with saline into the left ovary and right hemi-ovariectomized ( $1.3 \pm 0.25$ versus $4.8 \pm 0.4, P<0.01$, Mann-Whitney $U$ test). In the left ovary, several preovulatory follicles were present, and all presented signs of atresia.

The injection of saline or Xylocaine into the bursa of the right ovary affected neither the number of ovulating animals nor the number of ova recovered per ovulating animal (Table 4).

The injection of hCG at 14:00 h into rats treated with Xylocaine on the left ovary and then hemi-ovariectomized, partially restored ovulation ( $4 / 5$ animals presented fresh corpora lutea, and the mean number was $1.8 \pm 0.8$ ). In only two animals were ova recovered in the oviduct (mean: 2.5 ova). In the ovary of two animals, fresh corpora lutea with trapped ova were observed. When injection of Xylocaine into the left ovary and extirpation of the right ovary were performed at 18:00 h, all the animals ovulated normally ( $6 / 6$ ovulated, and the mean number of ova shed was $5.2 \pm 0.8$ ).

The ovulation rates (left ovary in situ 5/7; right ovary in situ 4/5) and number of ova shed (left ovary in situ $4.0 \pm 0.8$; right ovary in situ $5.3 \pm 0.5$ ) were not modified in those animals in which Xylocaine was injected into one ovary and the same ovary was extirpated 2 min later.

\section{Discussion}

The results of the present study suggest that during the afternoon of pro-oestrus, the left and right ovaries exchange some form of neural information necessary for the release of $\mathrm{LH}$ by the pituitary and for the normal response of the ovaries to $\mathrm{LH}$.
This interpretation is based on the following findings. In the intact animal, the manipulation of one ovary did not affect ovulation. The injection of Xylocaine in the left ovary and the injection of saline in the right ovary results in a decrease in the number of ova shed by both ovaries. Because this effect was not observed when the right ovary was injected with Xylocaine and the left ovary with saline, we propose that the initial signal originates in the left ovary. When both ovaries were injected with Xylocaine or saline, ovulation was normal in both ovaries, suggesting that other mechanisms are able to close the circuit necessary for normal ovulation.

Since in hemispayed animals, ovulation was affected only in those animals with the left ovary injected with Xylocaine, and the right ovary extirpated, it seems that such a signal needs two steps: the first step in the left ovary and a second step in the right ovary. The hypothesis that the blockade of innervation affects the response of the ovary to LH is supported by the incomplete ovulation observed in those hemi-ovariectomized animals treated with hCG. The neural information provided at a given time in relation to the secretion of $\mathrm{LH}$ is supported by the results obtained in those animals in which hemi-ovariectomy and anaesthesia were performed at 18:00 h.

Engeland et al. (1985), Engeland and Dallman (1976) and Holzwarth et al. (1987) observed that in the adrenal, innervation plays a role in the regulation of the response of endocrine organs to pituitary hormones. However, another possibility is that Xylocaine anaesthesia or saline injection affects ovarian vascularity. Zackrisson et al. (1996) have shown that the acute ligation of the ovarian artery of the ovarian branch of the uterine artery reduces the number of ova shed by the ovulating rats and that, in prepubertal rats primed with equine chorionic gonadotrophin (eCG) injected with hCG, sham operation to the arteries does not affect ovulation rate. However, a vascular interpretation does not explain the present results, since Xylocaine anaesthesia or saline injection affected ovulation only when the left ovary was injected with Xylocaine and the right ovary with saline. There is also evidence indicating differences in venous drainage between the right and left ovary (Reynolds, 1973). In addition, there is evidence that the sympathetic adrenal denervation modifies the adrenal blood flow without altering the increase in cortisol plasma concentration that is the response to haemorrhage (Engeland et al, 1985).

When a similar study was carried out in hemiovariectomized animals, the differences between the left and right ovaries were more evident. As was noted in previous studies, the left ovary seems more 'dependent' on neural signals when the right ovary is absent. The hypothesis that some neural information modulates the response of follicles to $\mathrm{LH}$ is supported by the finding that injection of hCG $\mathrm{I} \mathrm{h}$ after Xylocaine administration to the left ovary did not induce ovulation, and that fresh corpora lutea, with and without trapped ova, were observed. The dose of hCG used in the present study is enough to induce ovulation in pro-oestrous rats treated with sodium pentobarbital at 13:00 h ( $R$. Domínguez, unpublished). The temporality of the neural signal for the regulation of follicular sensitivity to $\mathrm{LH}$ is supported by the normal ovulation observed in those animals when Xylocaine was injected into the left ovary at 18:00 h. 
The finding that normal ovulation occurred in rats in which anaesthesia of the left ovary was followed by extirpation of the 'anaesthetized' ovary supports the proposed existence of a neural signal, elicited in these animals by the extirpation of the left ovary, between the two ovaries.

On the basis of the results of the present study and those published earlier by the present authors and others, our hypothesis is that during the oestrous cycle, and particularly on the afternoon of pro-oestrus, the left ovary sends a signal to the right ovary that, in turn, relays a neural signal to the central nervous system arriving at the hypothalamus (Cruz ef al., 1990a, b; Morán et al., 1994), the mesencephalic central grey matter (Kawakami and Ando, 1981; Bergen and Leung, 1987a, b; Domínguez-González and Chávez, 1993, 1994), the AI region (Kawakami et al., 1981; Kaba et al., 1983; Tanaka et al., 1985), the dorsal raphe nucleus (Ayala et al., 1994) or the amygdala (Sánchez and Domínguez, 1995), originating another neural signal directed to the left and right ovaries via the superior ovarian nerve, which modulates the response of the ovaries to LH that results in ovulation.

In conclusion, the present results suggest that on the afternoon of the day of pro-oestrus, before the LH peak, a neural signal modulates the response of the left ovary to gonadotrophins.

Supported by DGAPA: grants IN208996, IN210893; CONACYT: grant IN1719 and Programa Universitario de Investigación en Salud, UNAM.

\section{References}

Ayala ME and Domínguez R (1988) Ovulation response to the sequential administration of the follicle stimulating hormone and human chorionic gonadotropin by autografted ovary in unilaterally ovariectomized adult rat with peripheral denervation induced by guanethidine treatment La revista de Investigación Clínica (Mexico) 40 149-155

Ayala ME, Rosas P and Domínguez R (1994) Different effects of unilateral and bilateral lesions of the dorsal raphe nucleus on puberty and first ovulation Brain Research Bulletin 34 27-30

Bergen $\mathbf{H}$ and Leung PCK (1987a) Electrical stimulation of ventral versus dorsal mesencephalic tegmental areas in the conscious rat: effects on luteinizing hormone release Neuroendocrinology 46 117-124

Bergen $\mathrm{H}$ and Leung PCK (1987b) Electrical stimulation of ascending noradrenergic tract in the midbrain: suppression of steroid-induced luteinizing hormone release Endocrinology 122 899-905

Bernstein LM (1993) Topoendocrinology Journal of Endocrinology 137 163-166

Burden HW (1985) The adrenergic innervation of mammalian ovary. In Catecholamines as Hormone Regulators pp 261-278 Eds N Ben-Jonathan, JM Bahr and RI Weiner. Raven Press, New York

Chávez R and Domínguez R (1994) Participation of the superior ovarian nerve in the regulation of compensatory ovarian hypertrophy: the effects of its section performed on each day of the oestrous cycle Journal of Endocrinology 140 197-201

Chávez R, Cruz ME and Dominguez R (1987a) Modifications on the ovarian response to gonadotropins induced by catecholamine depletion in vagotomized adult rats La Revista de Investigación Clinica (Mexico) 39 149-153

Chávez R, Cruz ME and Domínguez R (1987b) Ovulation and compensatory ovarian hypertrophy $(\mathrm{COH})$ to gonadotropins depends on the vagus nerve and catecholaminergic ovarian innervation Medical Science Research 15 $1529-1530$

Chávez R, Cruz ME and Domínguez R (1987c) Differences in the ovulation rate of the right and left ovary in unilaterally ovariectomized rats: effects of ipsi and contralateral section of the vagus nerves on the remaining ovary journal of Endocrinology $113397-401$
Chávez R, Carrizosa L and Dominguez R (1991) Effects of superior ovarian nerve section on spontaneous and induced ovulation in the adult rat Medical Science Research 19 41-42

Cruz ME, Chávez R and Domínguez R (1986) Ovulation, follicular growth and ovarian reactivity to exogenous gonadotropins in adult rats with unilateral or bilateral section of the vagi nerves La Revista de Investigación Clínica (Mexico) 38 167-171

Cruz ME, Morán JL, Jaramillo LP and Domínguez R (1990a) Differential effects of unilateral hypothalamic lesion on ovulation and compensatory ovarian hypertrophy in hemispayed adult rats Journal of Endocrinology 112 37-41

Cruz ME, Morán JL, Jaramillo LP and Dominguez R (1990b) Differences in spontaneous ovulation in rats with unilateral lesion of the hypothalamus Brain Research Bulletin 24 739-742

Domínguez R (1990) Different ovulatory response of the right and left ovary to unilateral lesion and anaesthesia of the cervico-vaginal plexus Journal of Endocrinology 124 43-45

Domínguez R and Riboni L (1971) Failure of ovulation in autografted ovary in hemispayed rat Neuroendocrinology 7, 164-170

Dominguez R, Cruz ME and Chávez R (1989) Differences in the ovulatory ability between the right and left ovary related to ovary innervation. In Growth Factors and the Ovary pp 321-325 Ed. AN Hirshfield. Plenum Press, New York and London

Domínguez-González A and Chávez R (1993) Asymmetric effects of unilateral lesions in the midbrain central gray matter on ovulation in the adult female rat Medical Science Research 21 513-514

Dominguez-González A and Chávez R (1994) Evidence of the participation of catecholaminergic system on the midbrain central gray matter on ovulation Medical Science Research 22 311-312

Engeland WC and Dallman MF (1976) Neural mediation of compensatory adrenal growth Endocrinology 99 1659-1662

Engeland WC, Shinsako J and Dallman MF (1976) Corticoids and ACTH are not required for compensatory adrenal growth American Journal of Physiology $\mathbf{2 2 9}$ 1461-1464

Engeland WC, Lilly MP and Gann DS (1985) Sympathetic adrenal denervation decreases adrenal blood flow without altering the cortisol response to haemorrhage Endocrinology 117 1000-1010

Espey LL and Lipner H (1994) Ovulation. In The Physiology of Reproduction 2nd Edn pp 725-780 Eds E Knobil and JD Neill. Raven Press, New York

Higuchi Y and Espey LL (1989) Pattern of ovarian steroid secretion during ovulation of in vitro perfused rat ovary varying with methods of sampling Journal of Reproduction and Fertility 87 821-828

Holtzwarth MA, Cunningham LA and Kleitman N (1987) The role of adrenal nerves in the regulation of adrenocortical function Annals of the New York Academy of Sciences 512 449-464

Hunter RHF, Cook B and Baker TG (1985) Intersexuality in five pigs, with particular reference to oestrous cycle, the ovotestis, steroid hormone secretion and potential fertility Journal of Endocrinology 106 233-242

Janson PO, Brännström M, Holmes PV and Sogn J (1988) Studies on the mechanisms of ovulation using the model of the isolated ovary Annals of the New York Academy of Sciences $\mathbf{5 4 1}$ 22-29

Kaba H, Saito H, Otsuka K, Seto K and Kawakami M (1983) Effects of estrogen on the excitability of neurons projecting from the noradrenergic $A 1$ region to the preoptic and anterior hypothalamic area Brain Research 274 156-159

Kawakami M and Ando S (1981) Lateral hypothalamic mediation of midbrain catecholaminergic influences on preovulatory surge of serum gonadotropin and prolactin in female rats Endocrinology 108 66-71

Kawakami M, Ando S, Nishihara M and Kadokoro Y (1981) Participation of the lower brain stem in induction of preovulatory gonadotropin surges in female rats Endocrinology Japonica $\mathbf{2 8} 809-818$

Morales L and Chávez R (1994) El nervio ovárico superior como modulador de la acción de las gonadotropinas. In Program of the XVIII Congreso Latinoamericano de Ciencias Fisiológicas Abstract P5/19 Montevideo, Uruguay

Morales L, Chávez R and Domínguez R (1993) Participation of the superior ovarian nerve in the regulation of ovulation in the prepubertal rat: differential effects of unilateral and bilateral section of the nerve Medical Science Research 21 15-17

Morán JL, Cruz ME and Domínguez R (1994) Differences in the ovulatory response to unilateral lesion in the preoptic or anterior hypothalamic area performed on each day of the estrous cycle of the adult rat Brain Research Bulletin 33 663-668

Morse AM and Van Wagenen G (1936) Observations upon ovulation in primates American Journal of Obstetrics and Gynecology 32 823-832 
Ojeda SR and Aguado LI (1985) Adrenergic control of the prepubertal ovary: involvement of local innervation and circulation catecholamines. In Catecholamines as Hormones Regulators pp 293-310 Eds N Ben-Jonathan, JM Bahr and RI Weiner. Raven Press, New York

Potashnik G, Insler V and Meizner J (1987) Frequency, sequence, and side of ovulation in women menstruating normally British Medical Journal 294219

Reynolds SRN (1973) Blood and lymph vascular system of the ovary. In Handbook of Physiology and Endocrinology II, Part I pp 261-316 Eds RO Greep and EB Astwood. American Physiological Society, Washington DC

Sánchez MA and Domínguez R (1995) Differential effects of unilateral lesions in the medial amygdala on spontaneous and induced ovulation Brain Research Bulletin 38 313-317

Tanaka J, Kaba H, Saito $\mathbf{H}$ and Seto K (1985) Inputs from the A1 noradrenergic region to the hypothalamic paraventricular neurons in the rat Brain Research $335368-371$
Weiner S, Whright KH and Wallach EE (1975a) Selective ovarian sympathectomy in the rabbit Fertility and Sterility 26 353-362

Weiner S, Whright KH and Wallach EE (1975b) Studies on the function of denervated rabbit ovary: human chorionic gonadotropin-induced ovulation Fertility and Sterility 26 363-368

Weiner S, Whright KH and Wallach EE (1975c) Lack of effect of ovarian denervation on ovulation and pregnancy in the rabbit Fertility and Sterility 26 1083-1087

Wylie SN, Roche PJ and Gibson WR (1985) Ovulation after sympathectomy denervation of the rat ovary produced by freezing its nerve supply Journal of Reproduction and Fertility 26 369-373

Zackrisson U, Mikuni M, Makinoda S, Janson PO, Peterson CM and Brännström M (1996) Ovulation rate in the rat is decreased by acute ligation of the ovarian artery of the ovarian branch of the uterine artery Biology of Reproduction $\mathbf{5 4}$ (Supplement 1) Abstract 46 